\title{
Effects of polychlorobiphenyls, polybromodiphenylethers, organochlorine pesticides and their metabolites on vitamin A status in lactating grey seals
}

\author{
Marie Vanden Berghe ${ }^{a}$, Liesbeth Weijs ${ }^{\mathrm{b}, \mathrm{c}}$, Sarah Habran ${ }^{\mathrm{d}}$, Krishna Das ${ }^{\mathrm{d}}$, Céline Bugli ${ }^{\mathrm{e}}$, Stéphane Pillet ${ }^{\mathrm{f}}$, \\ Jean-François Rees ${ }^{a}$, Paddy Pomeroy ${ }^{g}$, Adrian Covaci ${ }^{b, c}$, Cathy Debier ${ }^{a, *}$ \\ a Institut des Sciences de la Vie, Université catholique de Louvain, Croix du Sud 2/L7.05.08, Louvain-la-Neuve B-1348, Belgium \\ ${ }^{\mathrm{b}}$ Toxicological Centre, University of Antwerp, Universiteitsplein 1, Wilrijk 2610, Belgium

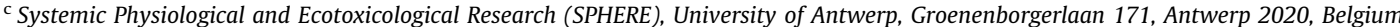 \\ ' Laboratoire d'Océanologie, Université de Liège, Allée de la Chimie 3, Liège 4000, Belgium \\ e Institut de statistique, Université catholique de Louvain, Voie du Roman Pays, 20, Louvain-la-Neuve 1348, Belgium \\ ${ }^{\mathrm{f}}$ Research Institute of the McGill University Health Center, Cedar Ave. 1650, \#R3, 117, Montreal (QC), Canada H3G1A4 \\ ${ }^{\mathrm{g}}$ Sea Mammal Research Unit, University of St Andrews, St Andrews, Fife KY16 9AJ, Scotland, United Kingdom
}

\section{A R T I C L E I N F O}

\section{Article history:}

Received 10 May 2012

Received in revised form

7 September 2012

Accepted 13 September 2012

Available online 7 October 2012

Keywords:

Grey seal females

Lactation

POPs

Metabolites

Vitamin A

\begin{abstract}
A B S T R A C T
Polychlorobiphenyls (PCBs), polybromodiphenylethers (PBDEs) and organochlorine pesticides (OCPs), such as dichlorodiphenyltrichloroethane (DDT) and hexachlorobenzene (HCB), are considered as endocrine disruptors in laboratory and wild animals. This study investigated whether these compounds and their hydroxylated metabolites (HO-PCBs and HO-PBDEs) may affect the homoeostasis of vitamin A, a dietary hormone, in the blubber and serum of twenty lactating grey seals sampled at early and late lactation on the Isle of May, Scotland. The effect of naturally produced compounds such as the methoxylated (MeO)-PBDEs was also examined. Vitamin A levels in inner blubber $(37 \pm 9 \mu \mathrm{g} / \mathrm{g}$ wet weight (ww) and $92 \pm 32 \mu \mathrm{g} / \mathrm{g}$ ww at early and late lactation, respectively) and serum (408 \pm 143 and $390 \pm 98 \mathrm{ng} / \mathrm{ml}$ at early and late lactation, respectively) appeared to be positively related to $\Sigma$ PCBs, $\Sigma$ PBDEs and several individual PCB and PBDE congeners in inner blubber and serum. These findings may suggest enhanced mobilisation of hepatic retinoid stores and redistribution in the blubber, a storage site for vitamin A in marine mammals. We have also reported that serum concentrations of $\Sigma$ HO-PCBs and 4-OH-CB107 tended to increase with circulating vitamin A levels. Although the direction of the relationships may sometimes differ from those reported in the literature, our results are in agreement with previous findings highlighting a disruption of vitamin A homoeostasis in the blubber and bloodstream following exposure to environmental pollutants. The fact that vitamin A and PCBs appeared to share common mechanisms of mobilisation and transfer during lactation in grey seals (Debier et al., 2004; Vanden Berghe et al., 2010) may also play a role in the different relationships observed between vitamin A and lipophilic pollutants.
\end{abstract}

(c) 2012 Elsevier Inc. All rights reserved.

\section{Introduction}

Persistent organic pollutants (POPs), such as polychlorobiphenyls (PCBs), polybromodiphenylethers (PBDEs) and organochlorine pesticides (OCPs), biomagnify in adipose tissue through the marine food web due to their persistence and lipophilicity (Law et al., 2003; Muir et al., 2003; Borja et al., 2005; Wolkers et al., 2006). Top

\footnotetext{
* Corresponding author. Fax: +3210473728.

E-mail addresses: marie.vandenberghe@uclouvain.be (M. Vanden Berghe), liesbeth.weijs@ua.ac.be (L. Weijs), S.Habran@ulg.ac.be (S. Habran), krishna.das@ulg.ac.be (K. Das), celine.bugli@uclouvain.be (C. Bugli), stephane.pillet@mail.mcgill.ca (S. Pillet), jf.rees@uclouvain.be (J.-F. Rees), pp6@st-andrews.ac.uk (P. Pomeroy), adrian.covaci@ua.ac.be (A. Covaci), cathy.debier@uclouvain.be (C. Debier).
}

predators, such as marine mammals, are therefore particularly sensitive to the accumulation of these pollutants that have been associated with reproduction impairment, endocrine disruption and/or immunotoxicity in several species (Sørmo et al., 2009; Letcher et al., 2010; Routti et al., 2010a). Various types of biomarkers for environmental contaminant exposure have been proposed in order to provide information on the overall health of marine mammals. Vitamin A (or retinol) represents one of these biomarkers (Simms and Ross, 2000). It is essential for vision, reproduction, immune functions, growth and development (Blomhoff, 1994; Debier and Larondelle, 2005) and a deficiency of this micronutrient induces important health consequences (West and Darnton-Hill, 2001).

The relationships between environmental pollutants and vitamin A homoeostasis have been well documented in humans, 
laboratory animals and wildlife species (Brouwer et al., 1998; Lans et al., 1993; Hallgren et al., 2001; Ellis-Hutchings et al., 2006; Novák et al., 2008). Most of these studies focussed on the impact of PCBs, and to a lesser extent of DDTs, HCB and PBDEs on vitamin A metabolism. Studies on laboratory and wild animals generally report depleted hepatic and adipose tissue retinoid stores as well as increased levels in the kidneys (Zile, 1992; Håkansson et al., 1994; Hallgren et al., 2001; Nyman et al., 2003; Ellis-Hutchings et al., 2006; Mos et al., 2007; Novák et al., 2008). In plasma, both an increase and a decrease of vitamin A levels have been observed, probably depending on the species, the physiological state and the concentrations at which the animals were exposed (Zile, 1992; Nyman et al., 2003; Novák et al., 2008; Cesh et al., 2010; Delport et al., 2011).

The mechanisms involved in the disruption of vitamin A homoeostasis by environmental pollutants are still not fully understood and a lot remains to be elucidated. Several environmental contaminants are known to disrupt the activity of enzymes involved in the storage, mobilisation and/or catabolism of vitamin $A$, interact with proteins of transport or alter the regulation of vitamin A nuclear receptors (Fig. 1). In the liver, contaminants such as 2,3,7,8-tetrachlorodibenzo-p-dioxin (TCDD), PCBs and pesticides were able to modulate the regulation of some cytochrome P450 (CYP) enzymes that are also involved in the metabolism and the catabolism of retinoic acid (Fig. 1, points 1 and 2) (Boyer et al., 2000, Leiva-Presa et al., 2006; Novák et al., 2008). The activity of enzymes that esterify retinol and hydrolyse retinyl esters such as retinyl ester hydrolase (REH), acyl-CoA:retinol acyltransferase (ARAT) and lecithin:retinol acyltransferase (LRAT) were also shown to be modulated by PCBs and TCDD in fish and laboratory animals (Fig. 1, points 3, 4 and 8) (Chen et al., 1992; Nilsson et al., 1996; Ndayibagira and Spear, 1999; Nilsson et al., 2000). In addition, some hydroxylated PCB metabolites (HO-PCBs) can interact with transthyretin (TTR), as reported in vivo and in vitro in humans and rats. TTR is a protein involved in the blood transport of thyroxin $\left(\mathrm{T}_{4}\right)$ and the retinol binding protein (RBP)-retinol complex. The binding of HO-PCBs to TTR instead of $\mathrm{T}_{4}$ lowers its affinity for the RBP-retinol complex, resulting in a greater urinary excretion of the RBP-retinol complex and thus a loss of vitamin A (Fig. 1, point 5) (Brouwer et al., 1998; Lans et al., 1993). Similar interactions between some hydroxylated PBDE metabolites (HO-PBDEs) and human TTR have been found in vitro (Meerts et al., 2000), suggesting that these metabolites may also be able to disrupt vitamin A homoeostasis (Fig. 1, point 5). Finally, PCBs and TCDD may affect vitamin A metabolism at the nuclear level as reported in human keratinocytes and seal blubber (Fig. 1, points 6 and 7) (Lorick et al., 1998; Mos et al., 2007).

Contrary to HO-PCBs, HO-PBDEs may result either from the biotransformation of synthetic PBDEs or be produced by marine sponges and algae (Wiseman et al., 2011). In addition, recent studies have shown that the demethylation of methoxylated polybrominated diphenyl ethers (MeO-PBDEs), compounds also naturally produced by marine organisms such as sponges and algae, could lead to the formation of HO-PBDEs, as demonstrated in vitro in microsomal fractions of several species of vertebrates (Wan et al., 2009; Wiseman et al., 2011). The presence of MeOPBDEs in marine organisms may therefore be of particular concern. MeO-PBDEs can biomagnify in the food chain and have been

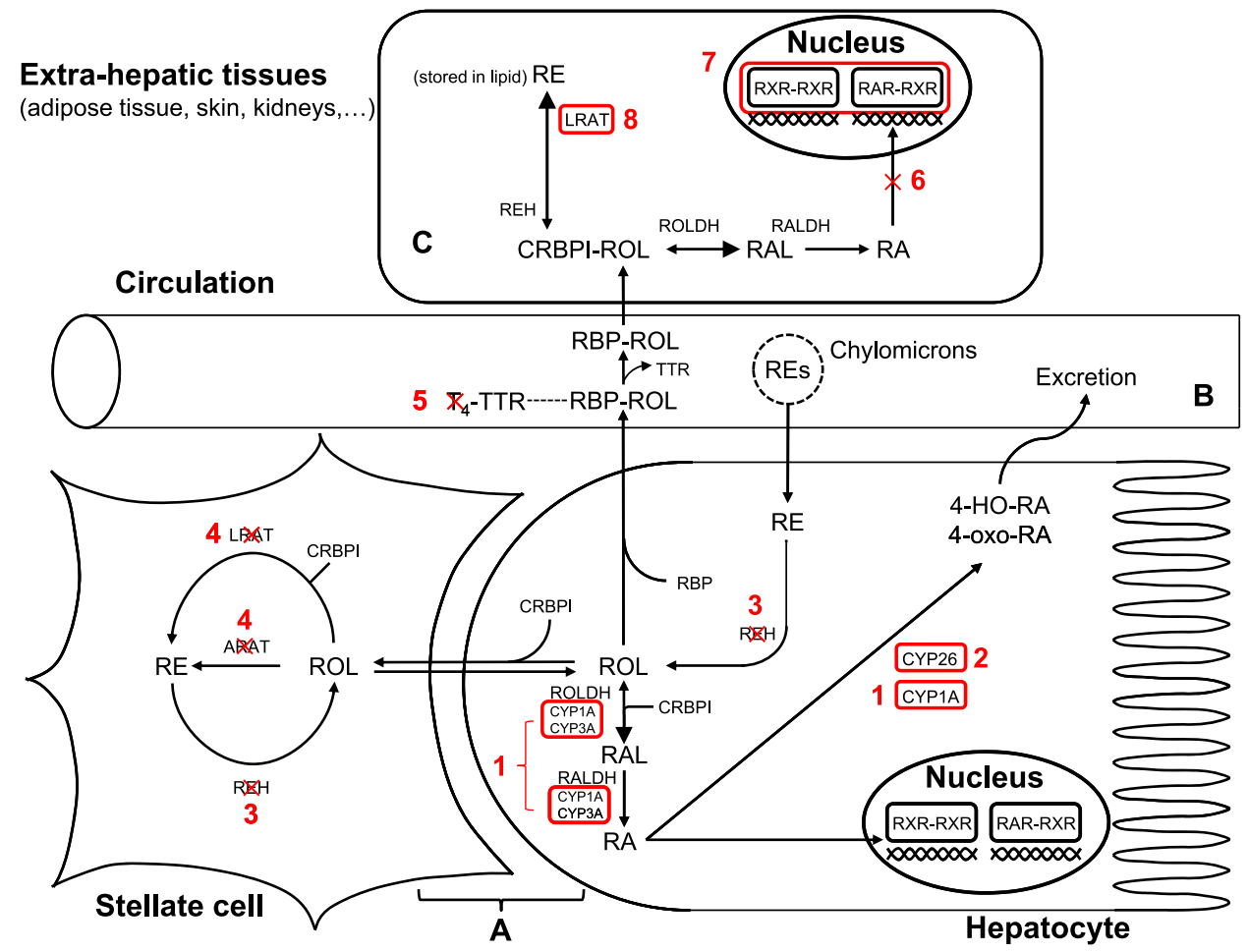

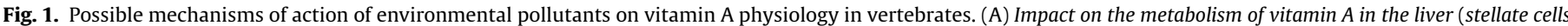

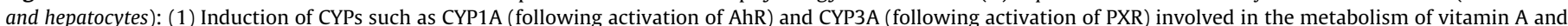

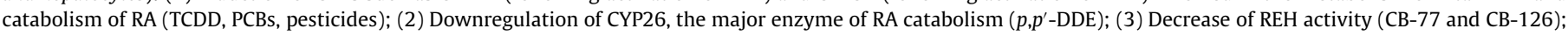

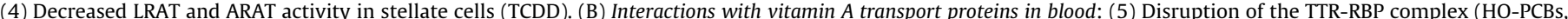

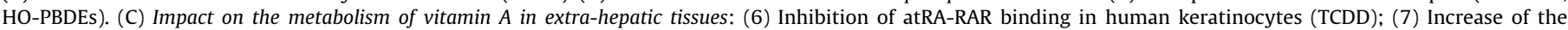

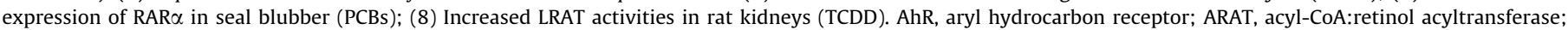

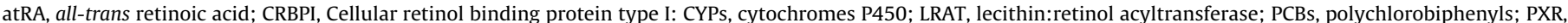

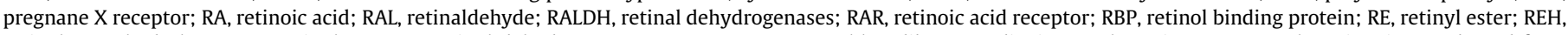

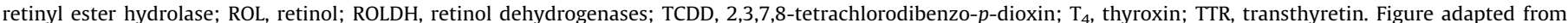
Ghyselinck et al. (1999), Simms et al. (2000) and Novák et al. (2008). 
measured in several marine mammals species, such as True's beaked whale (Mesoplodon mirus), beluga whale (Delphinapterus leucas), harbour porpoise (Phocoena phocoena) and harbour seal (Phoca vitulina) (Wolkers et al., 2004; Teuten et al., 2005; Weijs et al., 2009). In addition, the concentrations of MeO-PBDEs and especially tetrabrominated-MeO-PBDEs, have exceeded those of the anthropogenic PBDEs in several Australian marine mammals (Vetter et al., 2002).

While several studies investigated the effects of PCBs and DDTs on vitamin A metabolism in marine mammals (Nyman et al., 2003; Debier et al., 2005; Tornero et al., 2006; Mos et al., 2007; Routti et al., 2010b; Vanden Berghe et al., 2010), to our knowledge, none focussed on the relationships between vitamin A levels and PBDE contamination. However, PCBs and PBDEs share similar chemical properties and comparable adverse effects have been reported in several marine mammal species (Hall et al., 2003; Beineke et al., 2005; Peden-Adams et al., 2005). Furthermore, an impact of PBDEs on the status of vitamin A has been reported in laboratory animals, as well as in birds (Hallgren et al., 2001; Fernie et al., 2005; Ellis-Hutchings et al., 2006; Cesh et al., 2010). One can therefore assume that PBDEs may also affect vitamin A status in marine mammals.

The present study aimed to investigate the potential relationships between environmental pollutants (PBDEs, PCBs, their HOmetabolites and OCPs) and the levels of vitamin A in the blubber and serum of lactating grey seals (Halichoerus grypus). The relationships between the naturally produced MeO-PBDEs and vitamin A concentrations in maternal blubber and serum were also examined. Grey seals are characterised by having a short (from 16 to 21 days) and intense lactation period (Pomeroy et al., 1996). During that time, females produce milk extremely rich in lipids (up to $60 \%$ ), while fasting (Iverson et al., 1993; Pomeroy et al., 1996). Because females do not eat throughout the lactation, milk lipids derive only from their own body stores. The mobilisation of such huge amounts of lipids from blubber results in the release of lipophilic pollutants into the bloodstream of the lactating females (Debier et al., 2003, Sørmo et al., 2003; Vanden Berghe et al., 2010), exposing tissues to the potential harmful effects of these compounds. To our knowledge, this is the first study to examine the impact of PBDEs, HO-PCBs, HO-PBDEs and MeO-PBDEs on the vitamin $A$ status in a free-ranging marine mammal species during the lactation period.

\section{Material and methods}

\subsection{Seal Sampling}

Lactating grey seals from the Isle of May (IOM), Scotland, were studied during the breeding season in November-December 2008. Twenty females were captured and sampled at early (days 2-5) and mid-late (days 14-17) lactation in order to collect blubber and blood serum samples. Sampling techniques are described elsewhere (Debier et al., 2002a, 2003; Pomeroy et al., 1996). Briefly, blood samples were obtained from the extradural vein and blubber biopsies were taken from the lateral pelvic area of each female with a 6-mm biopsy punch. To protect vitamin A against UV light, samples collected from each female were directly stored in an individual light-tight container. Samples were then transported to the field laboratory where blood samples were centrifuged and serum was immediately transferred into light-tight Eppendorf tubes. Blubber samples for POP analyses were stored in aluminium foil while blubber samples for vitamin A analyses were placed into light-tight Eppendorf tubes. In the field laboratory, all the samples were frozen before being shipped on dry ice to Belgium, where they were stored at -80 and $-20^{\circ} \mathrm{C}$, for vitamin A and POP analyses, respectively.

\subsection{Vitamin A analysis}

Vitamin A in serum and blubber was extracted and analysed as described elsewhere (Debier et al., 2002b; Vanden Berghe et al., 2010). Briefly, three successive extractions with hexane were carried out on each serum sample. The extracts were pooled, evaporated and the residue was reconstituted with methanol. For blubber, approximately $150 \mathrm{mg}$ of each end of the biopsy (outer and inner parts) were saponified with ethanolic $\mathrm{KOH}$ under nitrogen. Each sample was then extracted twice with diethyl ether. The extracts were pooled and washed at least four times with MilliQ water before being filtered and evaporated. The residue was dissolved in methanol. Vitamin A concentrations were quantified with an external standard solution of retinol (for serum) or retinyl acetate (for blubber) in ethanol that underwent the same extraction procedure as the samples. Vitamin A was determined by high-performance liquid chromatography (HPLC)—DAD detector operated at $325 \mathrm{~nm}$ and equipped with a Supelcosil LC18 column $(25 \mathrm{~cm} \times 4.5 \mathrm{~mm} \times 5 \mu \mathrm{m})$. Vitamin A was eluted isocratically with a $100 \%$ metha-

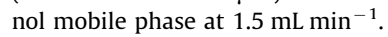

\subsection{Lipid and contaminant analysis}

Details on the lipid determination as well as the blubber and serum sample preparation, extraction, clean-up, quality assurance and chromatography analyses are described elsewhere (Vanden Berghe et al., 2012). In all samples, 35 PCB congeners (IUPAC numbers: CB-18, $-28,-44,-47,-49,-52,-87,-95,-99,-101,-105$, $-110,-118,-128,-138,-146,-149,-151,-153,-156,-158,-170,-171,-172,-174$ $-177,-180,-183,-187,-194,-195,-199,-205,-206$ and -209 ), six PBDEs (IUPAC numbers: BDE-28, $-47,-99,-100,-153$ and -154$)$, six DDXs (o, $p^{\prime}-$ DDD, $o, p^{\prime}-$ DDT $o, p^{\prime}-\mathrm{DDE}, p, p^{\prime}-\mathrm{DDD}, p, p^{\prime}-\mathrm{DDE}$, and $\left.p, p^{\prime}-\mathrm{DDT}\right), \mathrm{HCB}$ and two MeO-PBDEs (2'-MeOBDE-68 and 6-MeO-BDE 47) were measured. Additionally, 20 HO-PCBs were investigated in serum: $3 \mathrm{HO}-\mathrm{CB}(118,138,153$, and 180), 4HO-CB $(107,120,127$ $130,146,162,163,172,177,187,193,198,199,202$, and 208) and 4-di-HOCB202. The following three HO-PBDEs were targeted in all serum samples: 6-HOBDE47, 5-HO-BDE47 and 4-HO-BDE49.

\subsection{Statistical analyses}

Statistical analyses were conducted using SPSS 17 for Windows. Vitamin A and all contaminant levels were ln-transformed to normalise the data. Linear mixed models (LMM) were used to test the impact of pollutants on vitamin A concentrations. The individual was considered as a random explanatory variable, whereas the period of lactation, contaminant levels (on a lipid-weight basis for blubber and on a wet weight basis for serum), as well as the concentration of vitamin A in the "previous" tissue (e.g. vitamin A levels in inner blubber in order to explain vitamin A levels in serum) were included in the model as fixed variables. Some of the studied contaminants were highly inter-correlated in all investigated tissues (Table S1) and thus, could not be included together into the same statistical model in order to explain vitamin A variations. Therefore, we performed a different vitamin A model for each individual compound (e.g. CB-153, BDE-47 and $\left.p, p^{\prime}-\mathrm{DDE}\right)$, as well as for the sum of each class of contaminants ( $\Sigma$ PCBs, $\Sigma$ PBDEs, $\Sigma$ DDXs and $\Sigma \mathrm{MeO}-\mathrm{PBDEs}$ ). Only tables summarising the results for total contaminant concentrations are shown in Tables S2-4 in the Supplemented Information. The level of statistical significance was set at $p \leq 0.05$.

\section{Results}

Details concerning POP levels and profiles, as well as lipid contents in maternal blubber and serum can be found elsewhere (Vanden Berghe et al., 2012).

Mean concentrations of total vitamin A in blubber and serum are reported in Table 1.

\subsection{Blubber}

There was no relationship between vitamin A and any of the investigated contaminants in outer blubber (Table S2). By contrast, vitamin A levels were positively related to $\Sigma$ PCBs, $\Sigma$ PBDEs,

Table 1

Mean concentrations \pm standard deviation of the total vitamin A concentrations in blubber and serum of 20 lactating grey seals.

\begin{tabular}{lcr}
\hline Tissues & \multicolumn{2}{l}{ Vitamin A concentrations } \\
\cline { 2 - 3 } & Early lactation & Late lactation \\
\hline Outer blubber $(\mu \mathrm{g} / \mathrm{g}$ ww) & $55 \pm 20$ & $61 \pm 18$ \\
Inner blubber $(\mu \mathrm{g} / \mathrm{g}$ ww) & $37 \pm 9$ & $92 \pm 32$ \\
Serum $(\mathrm{ng} / \mathrm{ml})$ & $408 \pm 143$ & $390 \pm 98$ \\
\hline
\end{tabular}



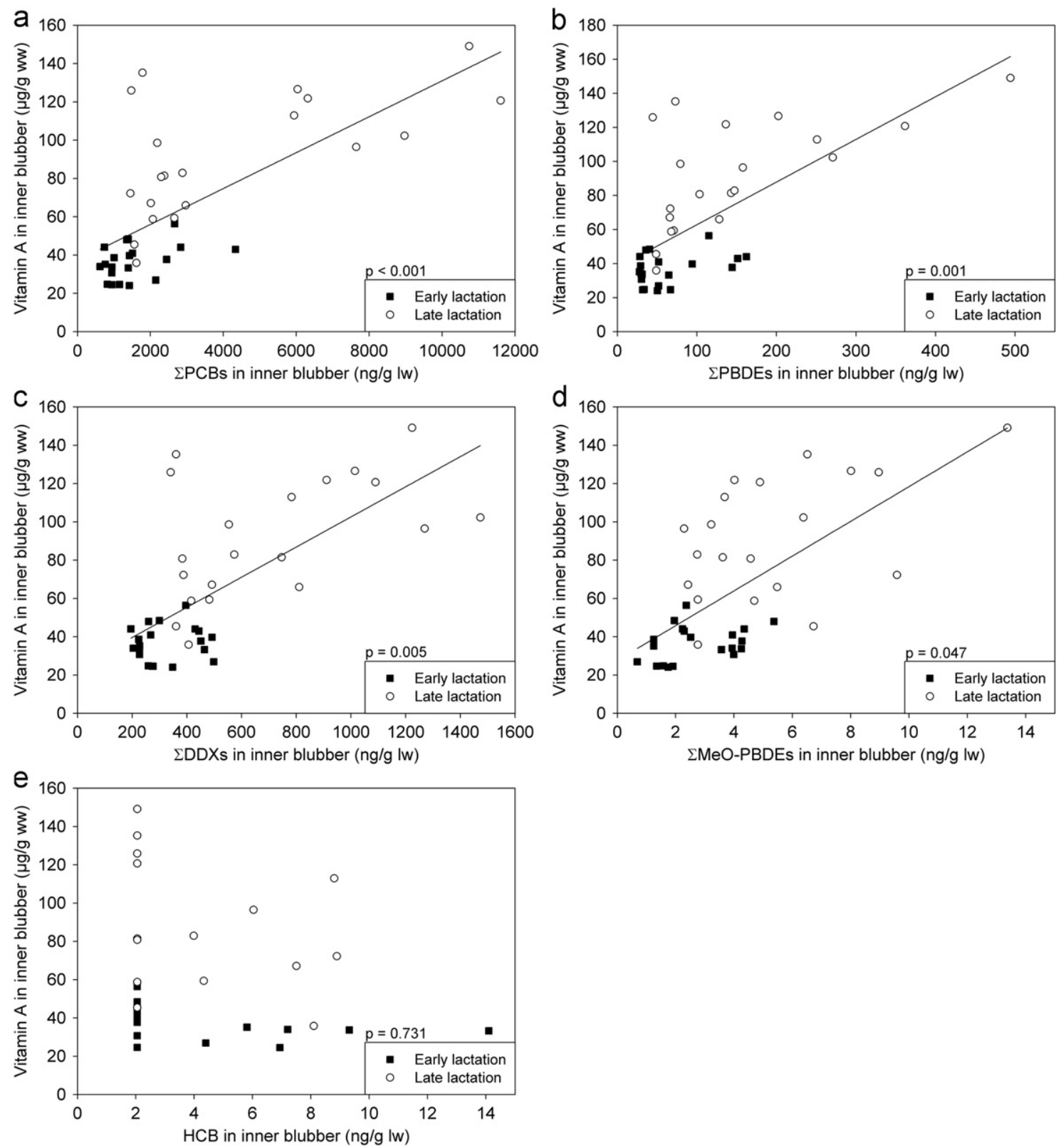

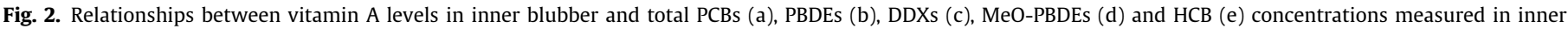
blubber of lactating grey seals. The $p$-values represent the level of significance of the linear mixed models which combined early and late lactation stages.

$\Sigma$ DDXs and $\Sigma$ MeO-PBDEs, but not to HCB, in inner blubber (Fig. 2 and Table S3). Concerning individual congeners, we observed that vitamin A was positively correlated ( $p$-values between $<0.001$ and 0.035 ) to all PCB congeners in inner blubber, except CB-18, $28,-47,-49$ and -110 . Vitamin $A$ in inner blubber was also positively correlated to all PBDE congeners measured in inner blubber ( $p$-values between $<0.001$ and 0.007), except BDE-28. Concerning DDXs, the correlation was positive only for $p, p^{\prime}$-DDE $(p=0.004)$. Finally, among MeO-PBDEs, a positive relationship was found only with $2^{\prime}-\mathrm{MeO}-\mathrm{BDE}-68$ in inner blubber $(p=0.023)$.

\subsection{Serum}

In serum, vitamin A concentrations were positively related to $\Sigma$ PCBs, $\Sigma$ PBDEs and $\Sigma$ HO-PCBs (Fig. 3 and Table S4). Significant relationships were found with several individual PCB congeners (CB-99, -101, -105, -118, -128, -138, -146, -149, -174, -177 and 187) ( $p$-values between 0.001 and 0.047 ). Among individual PBDE congeners and HO-PCB metabolites, positive relationships were observed between vitamin A levels and BDE-47 $(p=0.015)$ and 4HO-CB-107 ( $p=0.030)$. No correlation with either MeO-PBDEs or OCPs could be found. Relationships between vitamin A and HOPBDEs in serum could not be assessed because none of the investigated PBDE metabolites were detected in the present samples.

\section{Discussion}

We examined the relationships between vitamin A levels and the concentrations of PCBs, PBDEs, their metabolites and OCPs in the blubber and serum of lactating grey seals. Correlations with naturally produced $\mathrm{MeO}-\mathrm{PBDEs}$ were also investigated. The introduction of important factors, such as the period of lactation, in our LMM allowed the exclusion of the effects of time and thus, body mass and adipose lipid stores loss associated with lactation. 

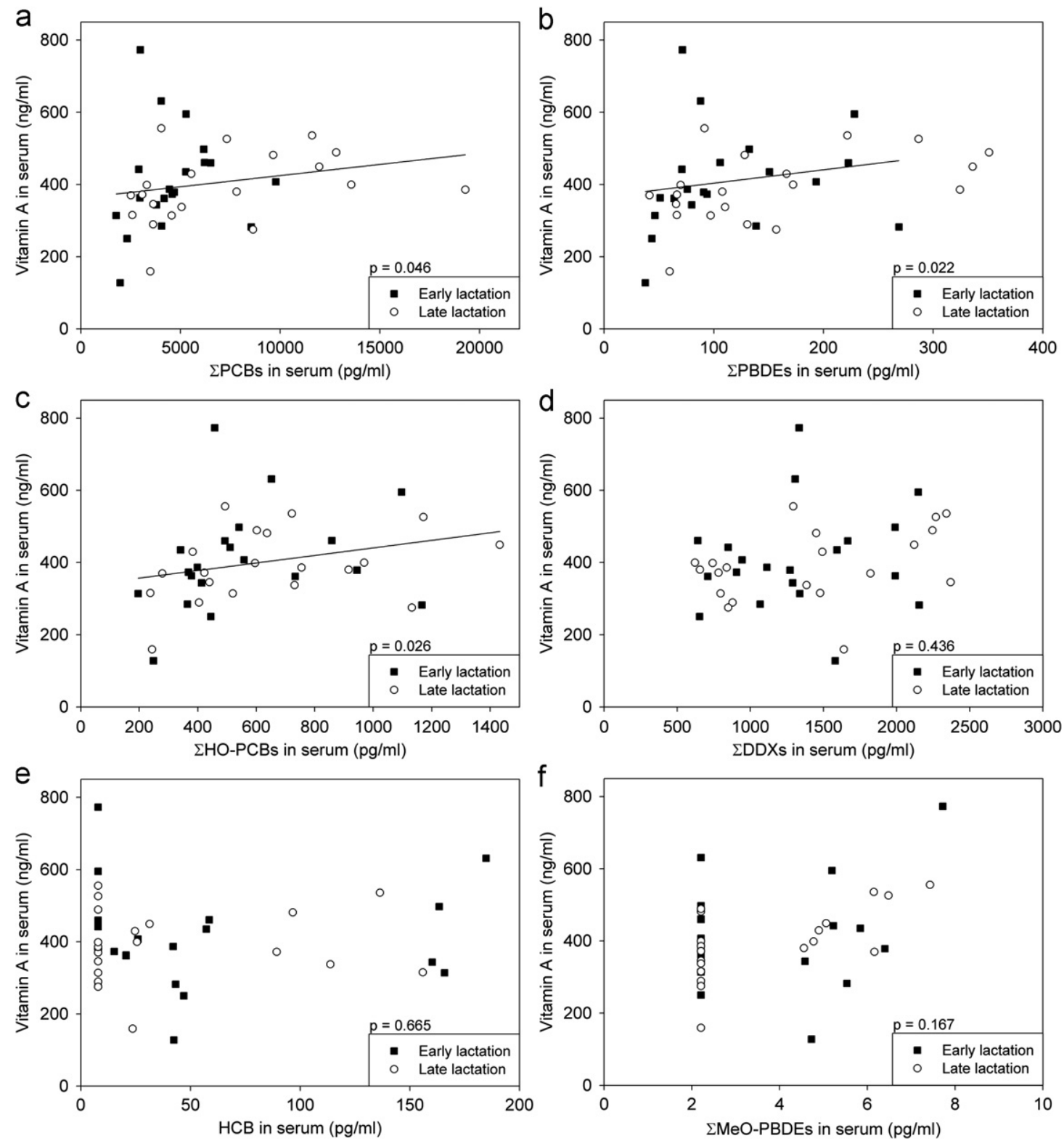

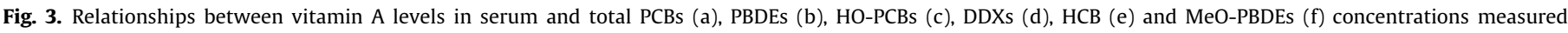
in serum of lactating grey seals. The $p$-values represent the level of significance of the linear mixed models which combined early and late lactation stages.

Although several studies have already examined the relationships between vitamin A and PCBs or OCPs in seals (Nyman et al., 2003; Jenssen et al., 2003; Debier et al., 2005; Mos et al., 2007; Vanden Berghe et al., 2010), this is the first study to explore the relationships between vitamin A and PBDEs, HO-PCBs and MeO-PBDEs in lactating seals.

\subsection{Relationships between PCBs, HO-PCBs and vitamin A}

Significant positive associations were found between vitamin A concentrations and $\Sigma$ PCBs, as well as with most individual PCB congeners in inner blubber, except those which were found in less than $50 \%$ of the blubber samples, e.g. CB-18, $-28,-47,-49$ and -110 (Vanden Berghe et al., 2012). This indicates that, regardless of the period of lactation, females with higher PCB levels in their inner blubber also tended to have higher vitamin A concentrations in that same layer. In addition, circulating vitamin A concentrations were positively related to $\Sigma$ PCBs, as well as to some tetra-CBs (CB99, $-101,-105$ and -118 ), penta-CBs (CB-128, -138, -146 and -149) and hexa-CBs (CB-174, -177 and -187) measured in the serum. Vitamin A was also positively associated to serum levels of $\Sigma \mathrm{HO}-$ PCBs and 4-OH-CB107, the major HO metabolite detected in serum (Vanden Berghe et al., 2012).

The relationships between PCBs and vitamin A status have been investigated in laboratory animals, as well as in wildlife. Several molecular mechanisms have been suggested and are summarised in Fig. 1. Increases in the circulating vitamin A after exposure to PCBs have already been reported in rats and were linked to a reduction of hepatic retinoid stores (Bank et al., 1989; Zile , 1992), suggesting an enhanced mobilisation of hepatic vitamin A in PCB exposed animals. A reduction of hepatic retinoid stores following PCB exposure has also been observed in fish (Boyer et al., 2000), birds (Bishop et al., 1999; Murk et al., 1994) and aquatic mammals (Murk et al., 1998; Nyman et al., 2003). Although several in vivo and in vitro studies showed that the activity of different liver enzymes involved in the retinoid metabolism were modified following PCB exposure (Fig. 1), the mechanisms by which an increased mobilisation of vitamin A from the liver may occur are still unknown. One explanation may lie 
in the decreased LRAT and ARAT activities, two enzymes involved in the conversion of retinol into retinyl esters in hepatic stellate cells (D'Ambrosio et al., 2011), and thus in the hepatic storage of vitamin A. Indeed, it has been shown that the treatment of rats with TCDD induced a decreased activity of LRAT and ARAT (Nilsson et al., 1996). As coplanar PCBs are agonists of the AhR in a similar way to TCDD and the impact of TCDD on vitamin A metabolism occurs entirely via AhR (Novák et al., 2008), coplanar PCBs, such as CB-105 and -118, may also be able to induce comparable enzyme inhibition. An additional contributory mechanism could be an increased release of retinol bound to RBP into the blood circulation (Zile , 1992). However, to the best of our knowledge, such a mechanism has not been described in detail.

Although liver vitamin A concentrations were not measured in the present study, it is possible that the positive relationships between PCBs and vitamin A observed here are due to an enhanced mobilisation of vitamin A from hepatic stores. The surplus released from the liver into the bloodstream could be either taken up by the kidneys, which play an important role in vitamin A metabolism (Käkëla et al., 1997) or stored in the blubber, which is an important storage site for vitamin A in marine mammals (Schweigert et al., 1987; Käkelä et al., 1997; Vanden Berghe et al., 2010). Nevertheless, in a similar study performed on Scottish grey seals, including the same seal population, Vanden Berghe et al. (2010) did not observe any relationship between PCBs and vitamin A levels in serum of lactating females, although comparable vitamin A and PCBs concentrations were measured in both studies. In that previous study, some individuals could not be sampled at each period. The number of samples was thus sometimes unequal for some animals and tissues, which may have lowered the statistical power to detect some effects. Additionally, our current analysis used a more rigorous LMM approach, whereas panel data regressions were performed in Vanden Berghe et al. (2010). The potential effects of PCBs on vitamin A in inner blubber could not be assessed in the previous study because there were too few matched samples for that tissue (11 out of 17 ).

Positive correlations between PCBs in blubber and circulating vitamin A were observed in weaned and fasted harbour seal pups (Simms et al., 2000). Similarly, Tornero et al. (2006) reported a positive correlation between retinoids and PCBs in the blubber of male common dolphins (Delphinus delphis). Individuals had, however, 10-fold higher PCB levels than in the present study. Both studies suggested an enhanced release of vitamin A from liver retinoid stores because of $\mathrm{PCB}$ contamination, contributing to increasing concentrations of vitamin $\mathrm{A}$ in blubber and serum. By contrast, Mos et al. (2007) found negative associations between PCBs and vitamin A levels in blubber of harbour seal pups exposed to similar PCB concentrations to the present study. Although Nyman et al. (2003) observed positive correlations between PCBs in liver and circulating vitamin A, they reported negative relationships between liver and blubber vitamin A contents and hepatic PCBs levels in grey seals. These studies suggested an increased mobilisation of vitamin A stores from the liver, but also from the blubber, leading to the depletion of vitamin A levels in these tissues and an increase of vitamin A in blood.

Most studies on seals report negative relationships between vitamin $\mathrm{A}$ and $\triangle \mathrm{PCB}$ concentrations in the circulation (Jenssen et al., 2003; Debier et al., 2005; Mos et al., 2007). Although these studies did not investigate the presence of circulating HO-PCBs, they suggest that the decrease in retinol concentrations was likely due to a disruption of the TTR-RBP-retinol complex by specific HO-PCBs. This can result in a greater excretion of circulating vitamin A by glomerular filtration, as observed in humans and laboratory animals (Brouwer et al., 1998; Lans et al., 1993) (Fig. 1). Several recent studies support this hypothesis. In a recent in vitro study using $\left[{ }^{125} \mathrm{I}\right]-\mathrm{T}_{4}$ and $\left[{ }^{14} \mathrm{C}\right]-4-\mathrm{OH}-\mathrm{CB} 107$, Gutleb et al. (2010) have shown that 4-OH-CB107 completely saturated the binding sites on TTR for $\mathrm{T}_{4}$ in wild living polar bears (Ursus maritimus). Nonetheless, the concentrations of 4-HO-CB107 detected in those polar bears were more than 25 times higher than levels detected in the seals of the present study (Vanden Berghe et al., 2012). Gabrielsen et al., 2011 reported negative relationships between several HO-PCBs and thyroid hormones in in vivo studies with hooded seals (Cystophora cristata). Similarly, although not demonstrated in wild mammals yet, Cesh et al. (2010) found negative correlations between HO-PCBs and retinol in plasma of nestling bald eagle (Haliaeetus leucocephalus). These observations favour a competitive binding of HO-PCBs to TTR in wild animals.

The positive correlations between $\mathrm{HO}-\mathrm{PCBs}$ and vitamin A observed in the present study do not mean that HO-PCBs did not exert an impact on the blood transport of vitamin $A$, through the binding to TTR. Indeed, other molecular mechanisms occurring at different levels (e.g. enzymes, nuclear receptors) in liver and/or blubber may also take place and be at the origin of the positive relationships observed. Moreover, contrary to the present study, the previously cited works were carried out on non-lactating animals and, except for the study of Simms et al. (2000), on nonfasting animals. Although the stage of lactation was used in our statistical models to control for temporal variation in lipid loss associated with lactation and fasting, lactation represents a physiological state associated with important metabolic adaptations. Therefore, other mechanisms may be at the origin of the positive relationships observed in our grey seal mothers. The fact that mobilisation and transfer of PCBs and vitamin A during lactation in grey seals appear to share common biochemical pathways may also contribute to the relationships observed in the present study (Debier et al., 2004; Vanden Berghe et al., 2010).

\subsection{Relationships between PBDEs, MeO-PBDEs and vitamin $A$}

Vitamin A concentrations in inner blubber were positively correlated with $\Sigma$ PBDEs, as well as with BDE-47, -99, -100, -153 and -154 . Similarly, positive relationships were observed in serum between vitamin A concentrations and $\Sigma$ PBDEs, as well as BDE-47, the prevalent PBDE congener found in the serum samples (Vanden Berghe et al., 2012). The positive relationships between vitamin A and PBDE levels in serum and blubber may result, in part, from an enhanced mobilisation of vitamin A from the liver, as suggested earlier for PCBs.

PBDEs have been shown to decrease hepatic retinoid levels in rats (Hallgren et al., 2001; Ellis-Hutchings et al., 2006), which may be explained in part by an enhanced vitamin A metabolism in the liver. For example, technical PBDE mixtures have been shown to induce both phase I and phase II xenobiotic metabolising enzymes in in vitro and in vivo experiments (Siddiqi et al., 2003) and may thus have adverse effects comparable to TCDD and dioxin-like PCBs on hepatic vitamin A homoeostasis. However, Sanders et al. (2005) reported only a weak up-regulation of CYP1A1 (a biomarker for activation of the AhR) by DE-71, a PBDE technical mixture, and BDE-47, -99 and -100 in rats exposed to high concentrations. On the contrary, PBDEs appeared to be more able to up-regulate CYP2B and CYP3A, both biomarkers for activation of Constitutive Androstane and Pregnane X Receptors (CAR and PXR, respectively). Sanders et al. (2005) suggested thus that PBDEs more likely mediate their toxicity through AhR-independent mechanisms. It has been shown recently that CYP3A was involved in the hepatic metabolism of retinoic acid (Ross and Zolfaghari, 2011), suggesting that PBDEs may affect vitamin A metabolism, in part, through this pathway. 
Mechanisms by which PBDEs may increase mobilisation of hepatic vitamin A have never been investigated. Few studies have analysed the effects of PBDEs on vitamin A status and most of them have been performed on laboratory animals or birds and often used non-environmentally relevant concentrations. Hallgren et al. (2001) showed that rats exposed to 18 and $36 \mathrm{mg} / \mathrm{kg}$ of Bromkal 70-5 DE, a technical mixture containing tetra- and penta-PBDEs (40\% of BDE47), had reduced hepatic vitamin A levels compared to controls. Although PBDE concentrations found in our grey seals are about 200 times lower, a comparable decrease following PBDE contamination may have occurred, leading to higher circulating vitamin A concentrations. However, although Ellis-Hutchings et al. (2006) also observed a significant decrease in vitamin A liver content in DE-71 exposed rats during gestation and lactation, no change in circulating retinol could be detected, suggesting that the mobilisation of vitamin A from the liver was not enhanced. Similarly, no significant correlation between $\Sigma$ PBDEs and retinol in blood plasma were found in bald eagles with levels of contamination 10 times higher than the grey seals of the present study (Cesh et al., 2010). On the other hand, American kestrels (Falco sparverius) exposed to environmentally relevant PBDE congener concentrations had lower plasma retinol levels when exposed to BDE-99 and -100, while reduced hepatic retinol and retinyl palmitate concentrations were observed when kestrels were exposed to BDE-47 (Fernie et al., 2005). The direction of the relationships between PBDEs and vitamin A appeared thus to be highly variable according to the species, the physiological status of the animal, but also the congeners/mixtures and the level of exposure.

Positive correlations were observed between vitamin A, $\Sigma \mathrm{MeO}-$ PBDE and 2-MeO-BDE-68 levels in inner blubber. Since this is the first study to investigate the relationships between vitamin $A$ and naturally produced $\mathrm{MeO}-\mathrm{PBDEs}$ in any living organism, comparison with the literature was not possible. Moreover, the toxicity of MeO-PBDEs is still unclear. Some in vitro studies on human cell lines observed alterations of enzyme activity such as CYP17 and aromatase (Cantón et al., 2005; 2006; Song et al., 2008). However, one major concern is likely the demethylation of MeO-PBDEs, which produces OH-PBDEs, a process that has been observed in some fish species (Wan et al., 2009). A competitive binding of HOPBDEs on human TTR has been demonstrated in vitro (Meerts et al., 2000) and negative relationships between $\Sigma$ HO-PBDEs and circulating retinol in bald eagles were observed (Cesh et al., 2010). Therefore, the presence of MeO-PBDEs in organisms may have toxicological implications for vitamin A homoeostasis. Nevertheless, HO-PBDEs were not detected in grey seals serum of the present study, although the limit of quantification was rather low $(5 \mathrm{pg} / \mathrm{ml})$. Other studies have also reported no or low concentrations of circulating HO-PBDEs in seals (Routti et al., 2009; Weijs et al., 2009) and the authors suggested either low biotransformation or low retention of those compounds. PBDEs were present at low concentrations in blubber and serum in our lactating grey seals (Vanden Berghe et al., 2012), so it is possible that HO-PBDEs are formed at only low rates. In addition, MeO-PBDEs which may also be a source of HO-PBDEs (demethylation) were also detected at low concentrations in blubber and were absent in serum (Vanden Berghe et al., 2012). The low concentrations or absence of two potential sources of HO-PBDEs may explain the absence or undetectable levels of HO-PBDEs in serum.

\subsection{Relationships between OCPs and vitamin $A$}

Vitamin A concentrations in inner blubber were positively correlated with $\Sigma$ DDXs and with $p, p^{\prime}$-DDE in particular, the dominant DDX metabolite (Vanden Berghe et al., 2012). In serum, no effect of DDXs on vitamin A was observed. Similarly, no association between vitamin A concentrations and low levels of
HCB (Vanden Berghe et al., 2012) was found in any investigated tissues. In contrast to our results, Nyman et al. (2003) reported negative relationships between vitamin A and $\mathrm{DDDX}$ content in the liver but also in the blubber of grey seals. This decrease was coupled to an increase in circulating vitamin A. The authors suggested an exacerbated mobilisation of vitamin A from the liver and blubber, as already discussed for PCBs. On the other hand, vitamin A negatively correlated with $\Sigma$ DDX concentrations in serum of juvenile sea lions (Debier et al., 2005). Little is known about mechanisms of action of DDXs on vitamin A status. Delport et al. (2011) showed that long-term DDT uptake reduced RBP concentrations in human blood.

\section{Conclusions}

We observed positive relationships between vitamin $A$ and PCBs, PBDEs and DDXs in inner blubber and between vitamin $A$ and PCBs, PBDEs and HO-PCBs in serum of lactating grey seal females. These results suggest that vitamin A may be mobilised from the liver and redistributed into the blubber. Even though some of the relationships observed in the present study differed from previously published studies, our data corroborate previous findings showing that environmental contaminants may disrupt vitamin A homoeostasis in wild seals. Although the lactation was taken into account, this particular state very likely plays a role in the relationships between vitamin $A$ and pollutants. Among others, the fact that vitamin A and PCBs seem to be mobilised and transferred through similar pathways in lactating grey seals may contribute to the relationships observed. Finally, it is essential to remember that, in environmental studies, animals are exposed to a wide and complex mixture of compounds that interact with each other and that may interfere with the metabolism of vitamin A as mixtures or single compounds. The alteration of vitamin A status resulting from the exposure to environmental contaminants can affect the immune response with potential consequences on the resistance to infection at large (Mora et al., 2008). Moreover, direct effects of retinol on morbillivirus infections have recently been partially elucidated (Trottier et al., 2009). These impacts of vitamin A on marine mammal resistance to viral infections certainly deserve more attention. Additionally, it would be worth investigating the potential impacts of POPs and their metabolites in suckling pups. Indeed, in one of our previous works (Vanden Berghe et al., 2010), we showed that circulating vitamin A in suckling grey seal pups was adversely affected by PCBs found in milk and pup serum. These negative impacts on vitamin A status during a period of rapid growth and development could likely affect the health of young grey seals.

\section{Funding sources}

Marie Vanden Berghe is financially supported by the Fonds pour la formation à la Recherche dans l'Industrie et dans l'Agriculture (FRIA). Liesbeth Weijs and Adrian Covaci are financially supported by the Scientific Research Foundation (FWO)-Flanders. Krishna Das is a Fonds de la Recherche Scientifique (FRS)-FNRS Research Associate. The analytical part of the study was conducted thanks to the financial support of the FRS-FNRS (Fonds de la Recherche Fondamentale Collective (FRFC) project), Belgium. The field work in the UK was supported by UK Natural Environment Research Council (NERC) funding to Paddy Pomeroy and authorised under UK Home Office licence 60/3303. 


\section{Acknowledgments}

Simon Moss (SMRU) and the 2008 field teams are gratefully acknowledged. Marie Vanden Berghe is financially supported by the FRIA. Liesbeth Weijs and Adrian Covaci are financially supported by the FWO-Flanders. Krishna Das is a FRS-FNRS Research Associate. The analytical part of the study was conducted thanks to the financial support of the FNRS (FRFC project), Belgium. The field work in the UK was supported by UK NERC funding to PP and authorised under UK Home Office licence 60/3303.

\section{Appendix A. Supporting information}

Supplementary data associated with this article can be found in the online version at http://dx.doi.org/10.1016/j.envres.2012. 09.004.

\section{References}

Bank, P.A., Cullum, M.E., Jensen, R.K., Zile, M.H., 1989. Effect of hexachlorobiphenyl on vitamin A homeostasis in the rat. Biochim. Biophys. Acta-Gen. Subj. 990, 306-314.

Beineke, A., Siebert, U., Mclachlan, M., Bruhn, R., Thron, K., Failing, K., Muller, G. Baumgartner, W., 2005. Investigations of the potential influence of environmental contaminants on the thymus and spleen of harbor porpoises (Phocoena phocoena). Environ. Sci. Technol. 39, 3933-3938.

Bishop, C.A., Mahony, N.A., Trudeau, S., Pettit, K.E., 1999. Reproductive success and biochemical effects in tree swallows (Tachycineta bicolor) exposed to chlorinated hydrocarbon contaminants in wetlands of the great lakes and St Lawrence river basin, USA and Canada. Environ. Toxicol. Chem. 18, 263-271.

Blomhoff, R., 1994. Transport and Metabolism of Vitamin A. Nutr. Rev. 52, 13-23.

Borja, J., Taleon, D.M., Auresenia, J., Gallardo, S., 2005. Polychlorinated biphenyls and their biodegradation. Process Biochem. 40, 1999-2013.

Boyer, P.M., Ndayibagira, A., Spear, P.A., 2000. Dose-dependent stimulation of hepatic retinoic acid hydroxylation/oxidation and glucuronidation in brook trout, Salvelinus fontinalis, after exposure to 3,3',4,4'-tetrachlorobiphenyl Environ. Toxicol. Chem. 19, 700-705.

Brouwer, A., Morse, D.C., Lans, M.C., Gerlienke Schuur, A., Murk, A.J., KlassonWehler, E., Bergman, Ã.k., Visser, T.J., 1998. Interactions of persistent environmental organohalogens with the thyroid hormone system: mechanisms and possible consequences for animal and human health. Toxicol. Ind. Health 14 $59-84$

Cantón, R.F., Sanderson, J.T., Letcher, R.J., Bergman, Å., van den Berg, M., 2005. Inhibition and induction of aromatase (CYP19) activity by brominated flame retardants in H295R human adrenocortical carcinoma cells. Toxicol. Sci. 88 447-455.

Cantón, R.F., Sanderson, J.T., Nijmeijer, S., Bergman, A., Letcher, R.J., van den Berg, M., 2006. In vitro effects of brominated flame retardants and metabolites on CYP17 catalytic activity: a novel mechanism of action? Toxicol. Appl. Pharmacol. 216, 274-281.

Cesh, L.S., Elliott, K.H., Quade, S., McKinney, M.A., Maisoneuve, F., Garcelon, D.K. Sandau, C.D., Letcher, R.J., Williams, T.D., Elliott, J.E., 2010. Polyhalogenated aromatic hydrocarbons and metabolites: relation to circulating thyroid hormone and retinol in nestling bald eagles (Haliaeetus leucocephalus). Environ. Toxicol. Chem. 29, 1301-1310.

Chen, L.C., Berberian, I., Koch, B., Mercier, M. Azais-Braesco, V. Glauert, H.P. Chow, C.K., Robertson, L.W., 1992. Polychlorinated and polybrominated biphenyl congeners and retinoid levels in rat tissues: structure-activity relationships. Toxicol. Appl. Pharmacol. 114, 47-55.

D'Ambrosio, D.N., Clugston, R.D., Blaner, W.S., 2011. Vitamin A metabolism: an update. Nutrients 3, 63-103.

Debier, C., Larondelle, Y., 2005. Vitamins A and E: metabolism, roles and transfer to offspring. Br. J. Nutr. 93, 153-174.

Debier, C., Pomeroy, P.P., Baret, P.V., Mignolet, E., Larondelle, Y., 2002a. Vitamin E status and the dynamics of its transfer between mother and pup during lactation in grey seals (Halichoerus grypus). Can. J. Zool. 80, 727-737.

Debier, C., Pomeroy, P.P., Thomé, J.P., Mignolet, E., de Tillesse, T., Larondelle, Y., 2004. An unexpected parallelism between Vitamin A and PCBs in seal milk. Aquat. Toxicol. 68, 179-183.

Debier, C., Pomeroy, P.P., Van Wouwe, N., Mignolet, E., Baret, P.V., Larondelle, Y., 2002b. Dynamics of vitamin A in grey seal (Halichoerus grypus) mothers and pups throughout lactation. Can. J. Zool. 80, 1262-1273.

Debier, C., Pomeroy, P.P., Dupont, C., Joiris, C., Comblin, V., Le Boulenge, E. Larondelle, Y., Thome, J.P., 2003. Quantitative dynamics of PCB transfer from mother to pup during lactation in UK grey seals Halichoerus grypus. Mar. Ecol. Prog. Ser. 247, 237-248.

Debier, C., Ylitalo, G.M., Weise, M., Gulland, F. Costa, D.P. Le Boeuf, B.J., de Tillesse, T., Larondelle, Y., 2005. PCBs and DDT in the serum of juvenile California sea lions: associations with vitamins $\mathrm{A}$ and $\mathrm{E}$ and thyroid hormones. Environ. Pollut. 134, 323-332.

Delport, R., Bornman, R., MacIntyre, U.E., Oosthuizen, N.M., Becker, P.J., Aneck-Hahn, N.H., de Jager, C., 2011. Changes in retinol-binding protein concentrations and thyroid homeostasis with non-occupational exposure to DDT. Environ. Health Perspect. 119, 647-651.

Ellis-Hutchings, R.G., Cherr, G.N., Hanna, L.A., Keen, C.L., 2006. Polybrominated diphenyl ether (PBDE)-induced alterations in vitamin A and thyroid hormone concentrations in the rat during lactation and early postnatal development. Toxicol. Appl. Pharmacol. 215, 135-145.

Fernie, K.J., Shutt, J.L., Mayne, G., Hoffman, D., Letcher, R.J., Drouillard, K.G., Ritchie, I.J., 2005. Exposure to polybrominated diphenyl ethers (PBDEs): changes in thyroid, vitamin a, glutathione homeostasis, and oxidative stress in American kestrels (Falco sparverius). Toxicol. Sci. 88, 375-383.

Gabrielsen, K.M.l., Villanger, G.D., Lie, E., Karimi, M., Lydersen, C., Kovacs, K.M., Jenssen, B.r.M., 2011. Levels and patterns of hydroxylated polychlorinated biphenyls (OH-PCBs) and their associations with thyroid hormones in hooded seal (Cystophora cristata) mother-pup pairs. Aquat. Toxicol. 105, 482-491.

Ghyselinck, N.B., Båvik, C., Sapin, V., Mark, M., Bonnier, D., Hindelang, C., Dierich, A., Nilsson, C.B., Håkansson, H., Sauvant, P., Azaïs-Braesco, V., Frasson, M., Picaud, S., Chambon, P., 1999. Cellular retinol-binding protein I is essential for vitamin A homeostasis. EMBO J. 18, 4903-4914.

Gutleb, A.C., Cenijn, P., Velzen, M.V., Lie, E., Ropstad, E., Skaare, J.U., Malmberg, T., Bergman, Ã.K., Gabrielsen, G.W., Legler, J., 2010. In vitro assay shows that PCB metabolites completely saturate thyroid hormone transport capacity in blood of wild polar bears (Ursus maritimus). Environ. Sci. Technol. 44, 3149-3154.

Håkansson, H., Manzoor, E., Trossvik, C., Ahlborg, U.G., Chu, I., Villenueve, D., 1994. Effect on tissue vitamin A levels in the rat following subchronic exposure to four individual PCB congeners (IUPAC 77, 118, 126, and 153). Chemosphere 29, 2309-2313.

Hall, A.J., Kalantzi, O.I., Thomas, G.O., 2003. Polybrominated diphenyl ethers (PBDEs) in grey seals during their first year of life-are they thyroid hormone endocrine disrupters? Environ. Pollut. 126, 29-37.

Hallgren, S., Sinjari, T., Hakansson, H., Darnerud, P.O., 2001. Effects of polybrominated diphenyl ethers (PBDEs) and polychlorinated biphenyls (PCBs) on thyroid hormone and vitamin A levels in rats and mice. Arch. Toxicol. 75, 200-208.

Iverson, S.J., Bowen, W.D., Boness, D.J., Oftedal, O.T., 1993. The effect of maternal size and milk energy output on pup growth in grey seals (Halichoerus grypus). Physiol. Zool. 66, 61-88.

Jenssen, B.M., Haugen, O., Sørmo, E.G., Skaare, J.U., 2003. Negative relationship between PCBs and plasma retinol in low-contaminated free-ranging gray seal pups (Halichoerus grypus). Environ. Res. 93, 79-87.

Käkelä, R., Hyvärinen, H., Käkelä, A., 1997. Vitamins A1 (retinol), A2 (3,4didehydroretinol) and $\mathrm{E}$ ( $\alpha$-tocopherol) in the liver and blubber of lacustine and marine ringed seals (Phoca hispida sp.). Comp. Biochem. Physiol. B Biochem. Mol. Biol. 116, 27-33.

Lans, M.C., Klasson-Wehler, E., Willemsen, M., Meussen, E., Safe, S., Brouwer, A., 1993. Structure-dependent, competitive interaction of hydroxy-polychlorobiphenyls, -dibenzo-p-dioxins and -dibenzofurans with human transthyretin. Chem. Biol. Interact. 88, 7-21.

Law, R.J., Alaee, M., Allchin, C.R., Boon, J.P., Lebeuf, M., Lepom, P., Stern, G.A., 2003. Levels and trends of polybrominated diphenylethers and other brominated flame retardants in wildlife. Environ. Int. 29, 757-770.

Leiva-Presa, À., Mortensen, A.S., Arukwe, A., Jenssen, B.M., 2006. Altered hepatic retinol and CYP26 levels in adult European common frogs (Rana temporaria) exposed to $p, p^{\prime}$-DDE. Mar. Environ. Res. 62, S10-S15.

Letcher, R.J., Bustnes, J.O., Dietz, R., Jenssen, B.M., Jørgensen, E.H., Sonne, C., Verreault, J., Vijayan, M.M., Gabrielsen, G.W., 2010. Exposure and effects assessment of persistent organohalogen contaminants in arctic wildlife and fish. Sci. Total. Environ. 408, 2995-3043.

Lorick, K.L., Toscano, D.L., Toscano Jr, W.A., 1998. 2,3,7,8-tetrachlorodibenzo-pdioxin alters retinoic acid receptor function in human keratinocytes. Biochem. Biophys. Res. Commun. 243, 749-752.

Meerts, I.A.T.M., van Zanden, J.J., Luijks, E.A.C., van Leeuwen-Bol, I., Marsh, G., Jakobsson, E., Bergman, Ã.k., Brouwer, A., 2000. Potent competitive interactions of some brominated flame retardants and related compounds with human transthyretin in vitro. Toxicol. Sci. 56, 95-104.

Mora, J.R., Iwata, M., von Andrian, U.H., 2008. Vitamin effects on the immune system: vitamins A and D take centre stage. Nat. Rev. Immunol. 8, 685-698.

Mos, L., Tabuchi, M., Dangerfield, N., Jeffries, S.J., Koop, B.F., Ross, P.S., 2007. Contaminant-associated disruption of vitamin A and its receptor (retinoic acid receptor $\alpha$ ) in free-ranging harbour seals (Phoca vitulina). Aquat. Toxicol. 81, 319-328.

Muir, D., Savinova, T., Savinov, V., Alexeeva, L., Potelov, V., Svetochev, V., 2003. Bioaccumulation of PCBs and chlorinated pesticides in seals, fishes and invertebrates from theWhite Sea, Russia. Sci. Total Environ. 306, 111-131.

Murk, A.J., Bosveld, A.T.C., van den Berg, M., Brouwer, A., 1994. Effects of polyhalogenated aromatic hydrocarbons (PHAHs) on biochemical parameters in chicks of the common tern (Sterna hirundo). Aquat. Toxicol. 30, 91-115.

Murk, A.J., Leonards, P.E.G., van Hattum, B., Luit, R., van der Weiden, M.E.J., Smit, M., 1998. Application of biomarkers for exposure and effect of polyhalogenated aromatic hydrocarbons in naturally exposed European otters (Lutra lutra). Environ. Toxicol. Pharmacol. 6, 91-102.

Ndayibagira, A., Spear, P.A., 1999. Esterification and hydrolysis of vitamin A in the liver of brook trout (Salvelinus fontinalis) and the influence of a coplanar 
polychlorinated biphenyl. Comp. Biochem. Physiol. C Pharmacol. Toxicol. Endocrinol. 122, 317-325.

Nilsson, C.B., Hanberg, A., Trossvik, C., Håkansson, H., 1996. 2,3,7,8-Tetrachlorodibenzo-p-dioxin affects retinol esterification in rat hepatic stellate cells and kidney. Environ. Toxicol. Pharmacol. 2, 17-23.

Nilsson, C.B., Hoegberg, P., Trossvik, C., Azais-Braesco, V., Blaner, W.S., Fex, G. Harrison, E.H., Nau, H., Schmidt, C., van Bennekum, A.M., Håkansson, H., 2000. 2,3,7,8-Tetrachlorodibenzo-p-dioxin increases serum and kidney retinoic acid levels and kidney retinol esterification in the rat. Toxicol. Appl. Pharmacol. 169, 121-131.

Novák, J., Benísek, M., Hilscherová, K., 2008. Disruption of retinoid transport, metabolism and signaling by environmental pollutants. Environ. Int. 34 898-913.

Nyman, M., Bergknut, M., Fant, M.L., Raunio, H., Jestoi, M., Bengs, C., Murk, A. Koistinen, J., Backman, C., Pelkonen, O., Tysklind, M., Hirvi, T., Helle, E., 2003. Contaminant exposure and effects in Baltic ringed and grey seals as assessed by biomarkers. Mar. Environ. Res. 55, 73-99.

Peden-Adams, M., Romano, T., Rice, C., Lee, A., EuDaly, J., Mitchum, G., Bossart, G., Fair, P., 2005. Evaluation of brominated flame retardants in relationship to bottlenose dolphin immunity. J. Toxicol. Environ. Health A 67, 1517-1535.

Pomeroy, P.P., Green, N., Hall, A.J., Walton, M., Jones, K., Harwood, J., 1996. Congener-specific exposure of grey seal (Halichoerus grypus) pups to chlorinated biphenyls during lactation. Can. J. Fish Aquat. Sci. 53, 1526-1534.

Ross, A., Zolfaghari, R., 2011. Cytochrome P450s in the regulation of cellular retinoic acid metabolism. Annu. Rev. Nutr. 31, 65-87.

Routti, H., Letcher, R.J., Chu, S., van Bavel, B., Gabrielsen, G.W., 2009. Polybrominated diphenyl ethers and their hydroxylated analogues in ringed seals (Phoca hispida) from Svalbard and the Baltic Sea. Environ. Sci. Technol. 43, 3494-3499.

Routti, H., Arukwe, A., Jenssen, B.M., Letcher, R.J., Nyman, M., Bäckman, C., Gabrielsen, G.W., 2010a. Comparative endocrine disruptive effects of contaminants in ringed seals (Phoca hispida) from Svalbard and the Baltic Sea. Comp. Biochem. Physiol. C Toxicol. Pharmacol. 152, 306-312.

Routti, H., Jenssen, B.M., Lydersen, C., Bäckman, C., Arukwe, A., Nyman, M., Kovacs, K.M., Gabrielsen, G.W., 2010b. Hormone, vitamin and contaminant status during the moulting/fasting period in ringed seals (Pusa [Phoca] hispida) from Svalbard. Comp. Biochem. Physiol. A Mol. Integr. Physiol. 155, 70-76.

Sanders, J.M., Burka, L.T., Smith, C.S., Black, W., James, R., Cunningham, M.L., 2005. Differential expression of CYP1A, 2B, and 3A genes in the F344 rat following exposure to a polybrominated diphenyl ether mixture or individual components. Toxicol. Sci. 88, 127-133.

Schweigert, F.J., Stobo, W.T., Zucker, H., 1987. Vitamin A status in the grey seal (Halichoerus grypus) on Sable Island. Int. J. Vitam. Nutr. Res. 57, 239-245.

Siddiqi, M.A., Laessig, R.H., Reed, K.D., 2003. Polybrominated diphenyl ethers (PBDEs): new pollutants-old diseases. J. Clin. Med. Res. 1, 281-290.

Simms, W., Ross, P.S., 2000. Vitamin A physiology and its application as a biomarker of contaminant-related toxicity in marine mammals: a review. Toxicol. Ind. Health 16, 291-302.

Simms, W., Jeffries, S., Ikonomou, M., Ross, P.S., 2000. Contaminant-related disruption of vitamin A dynamics in free-ranging harbor seal (Phoca vitulina) pups from British Columbia, Canada, and Washington State, USA. Environ. Toxicol. Chem. 19, 2844-2849.

Song, R., He, Y., Murphy, M.B., Yeung, L.W.Y., Yu, R.M.K., Lam, M.H.W., Lam, P.K.S., Hecker, M., Giesy, J.P., Wu, R.S.S., Zhang, W., Sheng, G., Fu, J., 2008. Effects of fifteen PBDE metabolites, DE71, DE79 and TBBPA on steroidogenesis in the H295R cell line. Chemosphere 71, 1888-1894.

Sørmo, E.G., Larsen, H.J.R.S., Johansen, G.M., Skaare, J.U., Jenssen, B.R.M., 2009 Immunotoxicity of polychlorinated biphenyls (PCB) in free-ranging gray seal pups with special emphasis on dioxin-like congeners. J. Toxicol. Environ. Health A 72, 266-276.

Sørmo, E.G., Skaare, J.U., Lydersen, C., Kovacs, K.M., Hammill, M.O., Jenssen, B.M., 2003. Partitioning of persistent organic pollutants in grey seal (Halichoerus grypus) mother-pup pairs. Sci. Total Environ. 302, 145-155.

Teuten, E.L., Xu, L., Reddy, C.M., 2005. Two abundant bioaccumulated halogenated compounds are natural products. Science 307, 917-920.

Tornero, V., Borrell, A., Aguilar, A., Forcada, J., Lockyer, C., 2006. Organochlorine contaminant and retinoid levels in blubber of common dolphins (Delphinus delphis) off northwestern Spain. Environ. Pollut. 140, 312-321.

Trottier, C., Colombo, M., Mann, K.K., Miller Jr., W.H., Ward, B.J., 2009. Retinoids inhibit measles virus through a type I IFN-dependent bystander effect. FASEB J 23, 3203-3212.

Vanden Berghe, M., Weijs, L., Habran, S., Das, K., Bugli, C., Rees, J.F., Pomeroy, P. Covaci, A., Debier, C., 2012. Selective transfer of persistent organic pollutants and their metabolites in grey seals during lactation. Environ. Int. 46, 6-15.

Vanden Berghe, M., Mat, A., Arriola, A., Polain, S., Stekke, V., Thomé, J.-P., Gaspart F., Pomeroy, P., Larondelle, Y., Debier, C., 2010. Relationships between vitamin $\mathrm{A}$ and PCBs in grey seal mothers and pups during lactation. Environ. Pollut. 158, 1570-1575.

Vetter, W., Stoll, E., Garson, M.J., Fahey, S.J., Gaus, C., Müllerm, J.F., 2002. Sponge halogenated natural products found at parts-per-million levels in marine mammals. Environ. Toxicol. Chem. 21, 2014-2019.

Wan, Y., Wiseman, S., Chang, H., Zhang, X., Jones, P.D., Hecker, M., Kannan, K. Tanabe, S., Hu, J., Lam, M.H.W., Giesy, J.P., 2009. Origin of hydroxylated brominated diphenyl ethers: natural compounds or man-made flame retardants? Environ. Sci. Technol. 43, 7536-7542.

Weijs, L., Das, K., Siebert, U., van Elk, N., Jauniaux, T., Neels, H., Blust, R., Covaci, A., 2009. Concentrations of chlorinated and brominated contaminants and their metabolites in serum of harbour seals and harbour porpoises. Environ. Int. 35 842-850.

West Jr, K.P., Darnton-Hill, I., 2001. Vitamin A deficiency. In: Semba, R.D., Bloem, M.W. (Eds.), Nutrition and health in developing countries. Humana Press, Totowa, NJ, pp. 267-306.

Wiseman, S.B., Wan, Y., Chang, H., Zhang, X., Hecker, M., Jones, P.D., Giesy, J.P. 2011. Polybrominated diphenyl ethers and their hydroxylated/methoxylated analogues: environmental sources, metabolic relationships, and relative toxicities. Mar. Pollut. Bull. 63, 179-188.

Wolkers, H., Hammill, M.O., van Bavel, B., 2006. Tissue-specific accumulation and lactational transfer of polychlorinated biphenyls, chlorinated pesticides, and brominated flame retardants in hooded seals (Cistophora cristata) from the Gulf of St. Lawrence: applications for monitoring. Environ. Pollut. 142, 476-486.

Wolkers, H., Van bravel, B., Derocher, A.E., Wiig, Ø., Kovacs, K.M., Lydersen, C., Lindstrom, G., 2004. Congener-specific accumulation and food chain transfer of polybrominated diphenyl ethers in two arctic food chains. Environ. Sci. Technol. 38, 1667-1674.

Zile, M.H., 1992. Vitamin A homeostasis endangered by environmental pollutants. Proc. Soc. Exp. Biol. Med. Soc. 201, 141-153. 